\title{
The ideology of virtual space: Cildo Meireles, 1968-7
}

\begin{abstract}
Abigail McEwen
I was resting on a seat opposite [Claes] Oldenburg's Bedroom (1963) [Fig. 1] when I saw two wealthy-looking upper middle-class ladies from São Paulo admiring the piece. They had been talking as they came up but suddenly they fell silent. I was surprised by their reaction. They were dumbstruck, fascinated. ... Suddenly one of them turned to the other and said, 'How wonderful! How cute!' And finally one of them asked, 'Do you think we can buy something like this in São Paolo?' At that moment, I saw the problem of Pop Art very clearly: they didn't see the piece as a criticism but as a celebration. (Meireles 1999b: 138)
\end{abstract}

The optical ironies of Oldenburg's Bedroom Ensemble appeared vulnerable and carelessly self-referential to the young Brazilian artist Cildo Meireles (b. 1948) at the time of the 1967 São Paulo Biennial. A cloyingly domestic mise-en-scène, Bedroom celebrates the artifices of illusion. An anamorphosis in three dimensions, the room is built to the skewed proportions of a single-point perspective drawing, the furniture retaining the angles of the two-dimensional drawing on which it was based. Its hard surfaces and ersatz materials (imitation marble, vinyl sheets, fake fur) belie what Oldenburg recognised as the "softest room in the house", cooling the emotional valence of the home's most conventionally intimate space (Celant 1995: 204). Meireles questioned the integrity and intentionality of the installation, rejecting its spurious materials and geometry along with its too-easy commodification. Parsing through the logic of Pop, he began to identify for himself the crux of contemporary debates over the status of art and the nature of its objecthood.

The publication of Michael Fried's "Art and objecthood", just months before the opening of the São Paulo Biennial, brought renewed clarity to the discourse on

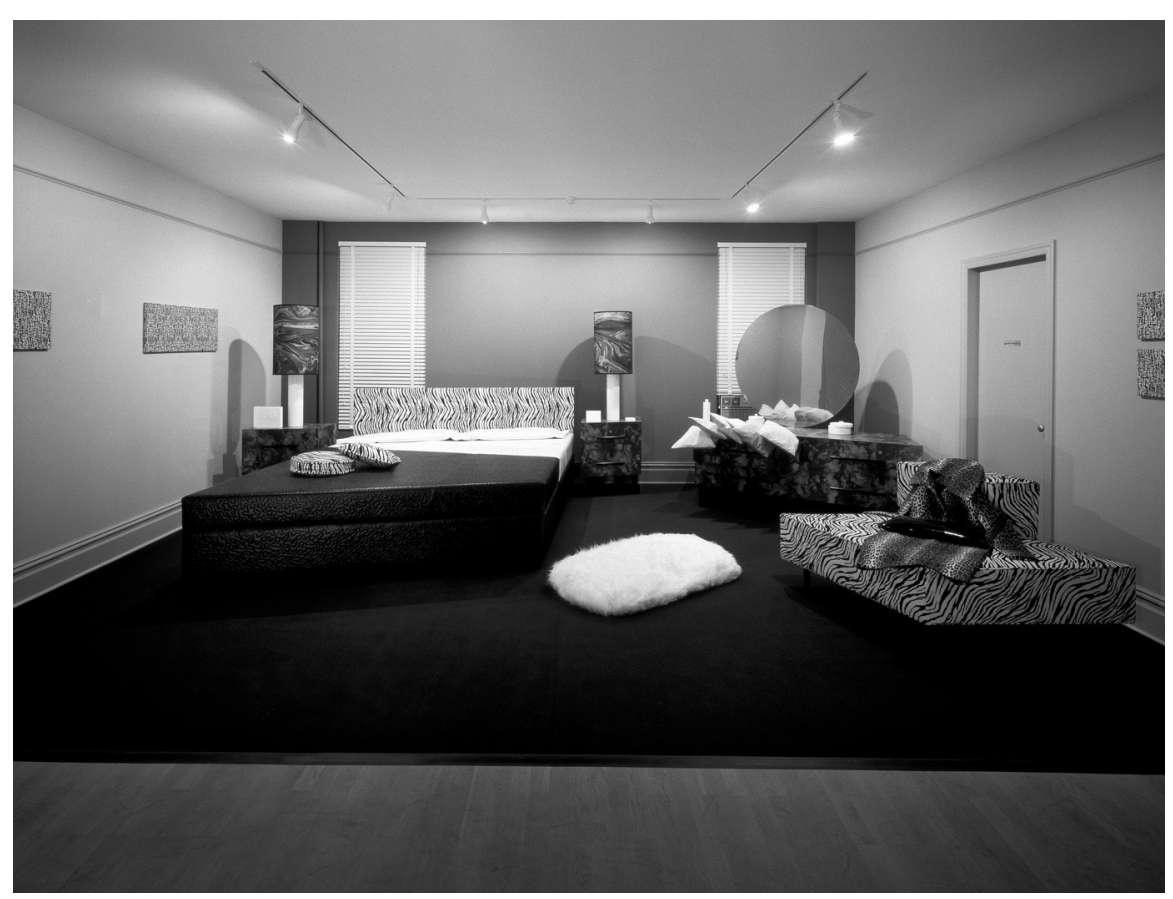

Fig. 1 Claes Oldenburg (1969). Bedroom Ensemble, Replica I [Courtesy: MMK Museum für Moderne Kunst Frankfurt am Main, former collection of Karl Ströher, Darmstadt; photo: Rudolph Nagel, Frankfurt am Main] 
Modernism and its limits, as brought to bear by the advent of American Pop art and Minimalism (Fried 1967). In Oldenburg's New York, the rise of the 1960s had seen new challenges to Modernist autonomy, as championed by formalist critics in support of mid-century American abstraction. The issues were not only ontological, which is to say formal and structural, but also functional and situational. Minimalism's confrontational insistence, its charged theatricality and complicity with its observer, fundamentally threatened the philosophical enterprise of Modernist art and its self-critical, medium-specific values of shape and opticality. The conditions of art-making and reception - no less, the values of art itself - were deeply fraught by the time of Meireles' visit to the Biennial. Bedroom Ensemble's flaunted pseudo-functionality, what Oldenburg described as its position "between what it seems to be and the work of art" (McDevitt 1965: 55), was enabled by its tacit withdrawal from both real-world and art-world contexts. Oldenburg emphasised the epistemic elusiveness of the work (hard or soft, angular or rectilinear, real or fake) as key to its independence, underscoring the irony of an exaggerated and reified illusionism as a riposte to the subjective experience of the work. The illusion is not in the object, Oldenburg explained, but in the eyes of the viewer (McDevitt 1965: 31). Bedroom Ensemble paid heavily for its autonomy, as Meireles understood, and its wilful indifference to context - its coy impermeability to its viewer and its setting - came at the price of its power over either one.

Oldenburg's concession was of an order that Meireles and the generation of artists that came of age in Brazil during the 1960s were unwilling to make. In Rio de Janeiro, the preceding rise of Neo-concretism had marked a break with the optical rationalisations of geometry, returning to the object its powers of mediation and, to its viewers, their full complement of senses. In their radical dematerialisations of the art object and phenomenological openness, the practices of artists such as Lygia Clark and Hélio Oiticica had opened a new horizon of possibility for art in the age of the "non-object". Defined by critic Ferreira Gullar in 1959, the non-object was premised on the continual and cumulative reconfiguration of space, understood no longer metaphorically but in real time (Gullar 1959). This re-cognitive function of the non-object, one that aimed to transform its space and simultaneously questioned the possibility of that transformation, served as a point of departure for the next wave of artists, who revisited in turn the communicative agency of its forms. Taking their cue not from abstraction but from Duchampian critique, lodged squarely in the logic of the art object itself, Meireles and his generation made explicit the power relations embedded within the open structure of the non-object. Alongside Brazilian contemporaries such as Artur Barrio and Waltercio Caldas, Meireles tested the parameters of art and, to a degree not met by their North American counterparts, defined early conceptualism in clear and ideologically topical terms. Indeed, the contingency of objects and of the systems in which they circulated became the urgent subject of Meireles' work by the later 1960s.

Meireles' destructuration of the object unfolded against the early years of Brazil's military regime (1964-85). He moved to Rio de Janeiro in early 1967 following a long adolescence in Brasília, the gleaming modernist metropolis created ex nihilo by Oscar Niemeyer and Lucio Costa under the presidency of Juscelino Kubitschek. The sinuous classicism of the city gave visible form to a new order of democracy and modernisation, upheld until the collapse of the Second Republic and the ensuing retreat from the utopian impulse it had embodied. Brazil's military dictatorship undoubtedly conditioned Meireles' early practice, both by providing a clear authority against which to act and, more suggestively, by stimulating the subtle, utopian dimension of his work. Acting in this contingent reality, he explored means by which to undermine and deinstitutionalise the power structures around 
him, and his work from this period engages utopia in its different pathological, imaginative and ironic forms. Although Meireles has repeatedly acknowledged the political critique of his work, the pessimism surrounding the time has obscured the degree to which utopia - ideology's recursive "other" - functioned as a powerful counter to his lived reality. Unlike the commodity materialism of Oldenburg or the coarse assemblages of Argentine Nueva Figuración, Meireles' insistent recourse to material referents - e.g., parquet flooring, Coca-Cola bottles, plywood - probed instead their impulse toward dematerialisation. His objects refuse to disappear, however, as they do in some contemporary conceptual practices, and their material fact served a necessary role in communicating his critical utopianism. The friction created at the boundary between the material and the immaterial effectively enabled Meireles to employ his "virtual spaces" and "ideological circuits" as strategies of political intercession.

By 1970 Meireles declared his work "no longer concerned with the object" at all and from that point forward a pure "practice", by which he meant a direct intervention into real and manifestly political space (Meireles 1999a: 113). This essay suggests the ways in which, over a period of approximately three years, Meireles came to define the terms of his practice around the axes of medium and mediation, on the one hand, and of ideology and utopia on the other. The materials of art took on new, functional significance within this revisionist ontology of art, in which contingency became central to the structure of the work itself. The seeming latency of his materials - suggested by their ordinariness, ephemerality and mutability - was in fact instrumental to their agency, foregrounding the work of art in real space and time. Focusing on three signal artworks of his early period - Virtual Spaces: Corners, Insertions into Ideological Circuits, and Tiradentes: Totem-Monument to the Political Prisoner - this essay describes how the dematerialised non-object came not only to intervene in a social system, but also to take the structure of a network, effectively turning the tables on the subject and object of the mediation. The oscillations of this network and its calibrated contingency suggest in turn an intervention into the spiralling ideological circle within and against which Meireles directed his work.

\section{Virtual Spaces: Corners, 1967-68}

Meireles drew compulsively - cathartically, he has allowed - during the mid1960s, but he began to consolidate his practice in a more deliberate way following his arrival in Rio de Janeiro, turning to graph paper to work out a new series, Virtual Spaces: Corners (Figs. 2, 3). A 44-piece project first conceptualised in these drawings, Virtual Spaces explored the phenomenon of virtual reality through a series of interventions into Euclidean space. In each case, Meireles presented planar axes of projection whose lines of convergence and near-convergence disfigure the regular right angle through perspectival distortions, creating unexpected, seemingly irrational envelopes of virtual space. The spatialised planes operate on the logic of the non-object, inserting themselves into the real space of the world only to transfigure it, creating in some cases structural ambiguities irresolvable in three dimensions and, in others, displacements of the corner through a kind of mental parallax. The transposition of the drawing into a built re-creation of a corner made the abstraction more concrete: the virtual space circumscribed by the off-angle junctions created a cognitive disconnect between the image that the viewers saw and that which they experienced (Figs. 4, 5). A plausible response to the internalised autonomy of Oldenburg's Bedroom, the Corners insist upon the contingency of viewing and, by extension, the position of the viewer. 
What prevented Virtual Spaces: Corners from slipping into a pure exegesis of spatial geometric or phenomenological problems was the specificity of the context in which the three-dimensional constructions were imagined to function. In 1968, Meireles built three models to scale from the series of drawings. Intended for the Paris Pre-Biennial, scheduled to open in May 1969 at the Museum of Modern Art in Rio de Janeiro but pre-emptively shut down hours before its opening ceremonies, the works were shown a few months later at the Salão da Bússola in the same venue. They were exhibited with the English title, "Nowhere is my Home", meant to be read alternately as "No, where is my home?" and "Now, here is my home" (Morais 2005: 35). The corners he chose to re-create were those of a domestic interior: a house with parquet floors, red baseboards and canvas-covered pink walls. The familiar, everyday setting of a household served as a foil to the real and increasingly unheimlich space on the other side of the corner, the non-autonomous and ideological space to which Meireles laid claim.
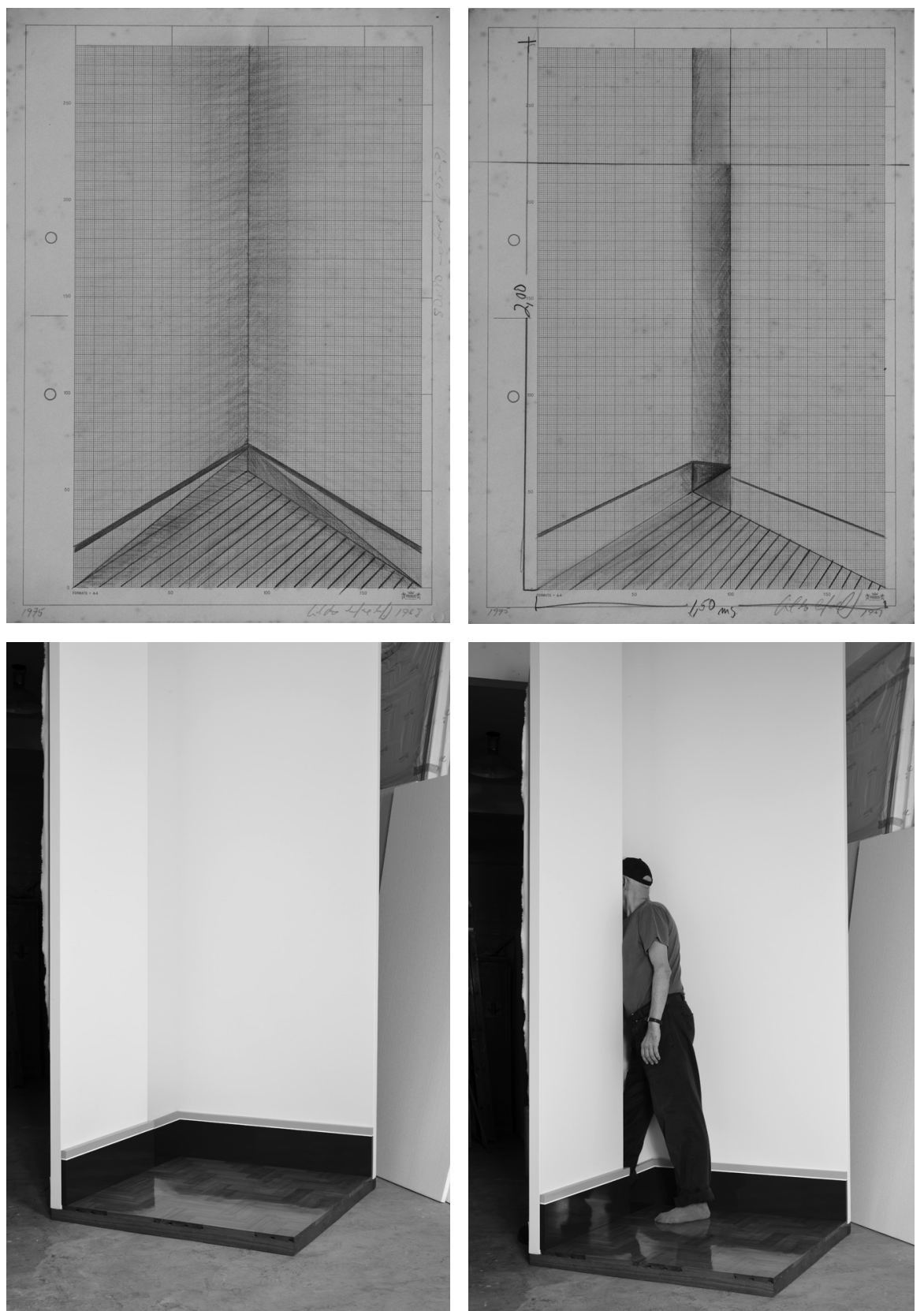

Fig. 2 and 3 Cildo Meireles (1968-75) Espaços virtuais: Cantos (Virtual Spaces: Corners) [Courtesy: Atelier Cildo Meireles]
Fig. 4 and 5 Cildo Meireles (1968-75). Espaços virtuais: Cantos IV(Virtual Spaces: Corners IV) [Courtesy: Atelier Cildo Meireles; photo: Pat Kilgore] 
A space of contingency but also of imagination, the virtual corner served practically to upset, or to call into question the new, normative status of the actual world that it bracketed. Meireles has explained that the series grew out of a dream experience that he first experienced as a child in his grandmother's home and that recurred years later at a bar in Rio de Janeiro: a woman appeared out of a corner of a room, collected herself, and vanished (Morais 2005: 32-3). The turn toward the oneiric and the imaginary, at a moment of ideological consolidation, acted here as a check on real power, one that suspended the inevitability of its course by questioning its, and our own, assumptions. As a form of utopian critique, the magic of this imaginary space circulated at the threshold of what was possible. Its fictionality - its absurdity, even - was part and parcel of its radicality, its audacity to dare replace the authority in power. Seen in a different way, the intimacy of the work's origins invites further meditations on the blurring of public and private space and of mind and matter. The spatial specificity of the dream is hardly incidental; its domestic authenticity acts as a foil to different constructions of virtual space (imagination, dream) and physical space (home, homeland, nation). The architectural space created by and between the two perpendicular walls elegantly mediates these spatial disjunctions through minimal, phenomenological means. Meireles' Virtual Space is ultimately actualised through the movement of the viewer-participant through the liminal break between the walls, a passage that amplifies the nexus between psychological, physical and public space.

This invisible boundary between the realisable and the impossible was in this way distilled in the virtual space of Meireles' corners, posited at the threshold of social reality and imagined utopia. The corners circumscribed a suggestively entropic and ideological space, but their metonymy seemed already a limitation to Meireles by 1968 , as he turned to what he described as "volatilized" forms meant to intervene directly into the public sphere. "I was no longer working with metaphorical representations of situations," he explained of his practice between 1968 and 1970. "I was working with the real situation itself" (Meireles 1999a: 110). The combustible Southern Cross (1969-70), a tiny pine-and-oak cube presented as a microcosm of friction and resistance, belongs to this transitional moment, but his most systemic critique manifested as Insertions into Ideological Circuits (1970-75). "Always one works with the possibility of transgressing reality," Meireles reflected at the time, "to make works that do not simply exist in an approved, consecrated space; that do not happen simply in terms of a canvas, a surface, a representation" (1999a: 113). His mandate carried new urgency by 1970, the start of what would be the five darkest and most oppressive years of Brazil's dictatorship.

\section{Insertions into Ideological Circuits, 1970-75}

What Virtual Spaces suggested to Meireles was how questions of medium turned less on the physicality of a support than on the specificity of the space in which the work acted. The three-dimensional Corners, for example, had posited a virtual feedback loop between the spatialised non-object, the intermediary viewer, and the social world. His next step was to eliminate the lingering subjectivity of the encounter - the imaginary projection required of the viewer - in favour of a purely autonomous artwork structured as a network itself. Insertions into Ideological Circuits consisted of two related interventions. The first, and for Meireles the more important, was the Banknotes project (Fig. 6), in which he removed paper currency from circulation, stamped it with different provocations and instructions, and put it back into circulation. Messages ranged from the admonishing "Yankees Go Home!" to the probing "Who Killed Herzog?", the latter the final reprise of the series and circulated in response to the 1975 assassination of the Brazilian journalist Wladimir 
Herzog, whose torture and murder were reported as a suicide. The companion project took aim not at the government but at industry and capitalism through the ubiquitous Coca-Cola bottle (Fig. 7). Meireles took ordinary, recyclable glass bottles out of circulation, used decals to silkscreen his message onto them, and then returned them to local centres for redistribution. As with the banknotes, the text invited further operations on the part of the viewer-collaborator, instructing: "Record critical information and opinions on the bottles and put them back into circulation." In both cases, the insertions into the consumerist circuit were a function of their use value (and materiality): only when the bottles were filled, or the banknotes spent, did their messages become easily legible and their real work begin.
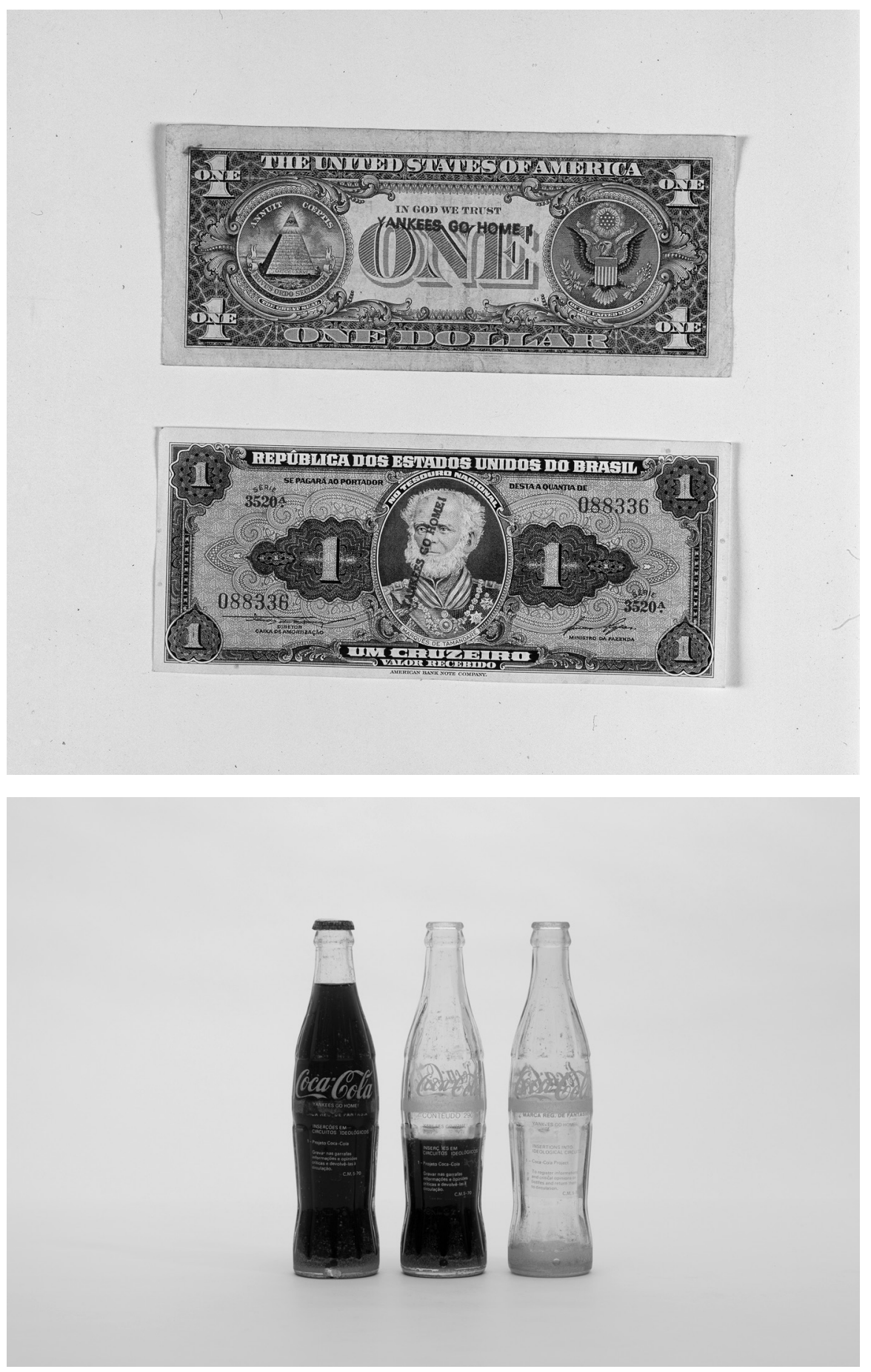

Fig. 6 Cildo Meireles (1970). Inserções em circuitos ideológicos: Projeto cédula (Insertions into Ideological Circuits: Banknote Project) [Courtesy: Atelier Cildo Meireles]

Fig. 7 Cildo Meireles (1970). Inserções em circuitos ideológicos: Projeto Coca-Cola (Insertions into Ideological Circuits: Coca-Cola Project) [Courtesy: Atelier Cildo Meireles; photo: Pat Kilgore] 
Insertions into Ideological Circuits arose out of a need, Meireles explained, "to create a system for the circulation and exchange of information that did not depend on any kind of centralized control" (1999a: 110). In April 1970, he wrote a text for Kynaston McShine's important early exhibition of conceptualism, Information, at the Museum of Modern Art in New York, that explained the rationale behind Insertions:

1. In society there are certain mechanisms for circulation (circuits)

2. These circuits clearly embody the ideology of the producer, but at the same time they are passive when they receive insertions into their circuits

3. This occurs whenever people initiate circuits (1999a: 110)

The self-sufficiency of the circuit, as Meireles understood it, invited a dialectical play with its interlocutors, and this state of constant interference (of "counter-information", in his words) was both transgressive and contingent (Meireles 1999a: 110-113). His abdication of control insinuated an anarchic, or despairingly nihilist, solution to the problem of power. Yet the ideological circuit also contained a vital utopian impulse, and the tension (and irony) sustained between autopoietic autonomy and imaginative reinscription marked this work with broader, ontological implications as well. Two points arise with respect to the changing status of an art practice that voluntarily relinquished its identification with material forms, yet could not operate without them. The first turns on questions of medium and on how an understanding of art as a system might alter our understanding of its work. The second considers the ideology of form and asks what was at stake in Meireles' retention of material referents for what had become an increasingly conceptual practice.

In structuring Insertions as a network, Meireles allowed the autonomy of the circuit - the quintessential non-object, as he knew - to unmask relations of power and their institutional apparatuses. The idea of the circuit was important to him, as it drew attention to the interconnections between art and the structure of social relations within which its forms were produced and received: "The container always carries with it an ideology", and as he further stated, stressing the performative work of the interventions on the public:

An insertion capitalizes on the sophistication of the medium in order to achieve an increase in equality of access to mass communication. Additionally, it brings about a transformation of the original ideological propaganda inherent in the circuit - whether produced by industry or by the state. The effect of this ideological circuit is like an anaesthetization of public consciousness. The process of insertion thus contrasts awareness (a result of the insertion) with anaesthesia (the property of the existing circuit). Awareness is seen as a function of art and anaesthesia as a product of the alienation inherent in industrialized capitalism. (1999a: 110)

In this sense, the circuit became a way of re-characterising the autonomy of art, seen not through the modernist paradigm of absorption and theatricality, but understood here as autopoeisis. The self-sufficiency of the Insertions effectively dissolved notions of agency and authorship: once Meireles set the banknotes and bottles into circulation, the dynamics of their play and perpetuation became at once boundless and self-determining. In appropriating the dialectical logic of the network as their own, the Insertions defined the terms of their critique through their medium, the process itself, and through the contingency of their co-opted material referents. 
Inasmuch as this process was virtualised and conceptually immaterial, as the Corners series anticipated, the targets of its work were tangible. As a form of social praxis, the action of Insertions against authority was clear: Meireles took as his target Brazil's military regime and sought to connect to and recuperate the mass public through these low-level interventions. He was careful, however, to distance his practice from proselytising, or propagandistic stratagem, insisting that even an explicitly political work "[had] to stand by itself as an art object, formally and conceptually". Yet the essential neutrality of the structure risked distortions and misreadings of his message: "to do nonproselytizing work," he allowed, "you open the space for someone to invert your intentions" (Farmer 2000: 36). The work of Insertions thus hinged on what Meireles called awareness, flickers or instantiations of consciousness in the alert viewer-participant that interrupted the numbing anaesthesia of ideology. In this way, the circuit may be seen not only as an open-ended process but also as a medium of consciousness. Less a question of cognition, or of more precise visual information, awareness in this context signified a groundedness in the real world. Meireles understood this embodiment effect as a precondition of his works' political critique, and the self-awareness invited by Insertions probed ontologies both of being and of art.

If the crux of the Insertions turned on this recursive relationship between mediation and medium (defined both as process and as embodiment), then the contingency of the work might be considered both sociological and existential in kind. The material transmission of the Coca-Cola bottles and the banknotes depended on institutional systems of exchange to facilitate the propagation of the circuit; as a viral operation, Insertions relied on the transactions made between the public and institutional bodies. The notional universality of their circulation was unquestionably a utopian construct, but even the plausibility of change, however impossible, served as a reality check against the distortions and estrangements of the state. In his Lectures on Ideology and Utopia, Paul Ricoeur noted the "paradox in [Karl] Mannheim that what characterizes utopia is not an inability to be actualized but a claim to shatter" (1987: 309). As a shattering of, or incursion into, consciousness, Insertions worked most productively on individuals who nevertheless knowingly immersed themselves in their day-to-day world, acknowledging the inevitability of their place within the circuit. Meireles could not presume the public's self-awareness, however, and an important contingency of Insertions was its wager on the will of its interlocutors to counteract the anaesthesia of power. "We cannot eliminate from social ethics the element of risk," Ricoeur allowed, and Insertions posited a twofold gambit: on the operations of pre-existing systems of exchange and, more critically, on the willingness of a body politic to not only be drawn into these ideological circuits, but to work against them (1987: 312).

The action of Insertions was thus in some way entropic by design, suggesting in theory the radical disordering and replacement of power relations rather than their reform or re-institutionalisation. The irony of this utopian premise lay in its liminal plausibility, or what Ricoeur alternately defined as the threshold between the sane (albeit fictional) and the insane (the pathological). The fictionality of Insertions, seen as a parallel microcosm of power, played out on a conceptual level, enacted in the transitive, virtual space of the circuit. In search of a more pathological intervention in 1970, Meireles made a one-off work, Tiradentes: Totem-Monument to the Political Prisoner, which tested the utility of contingency in an extreme and unrepeatable way. 


\section{Tiradentes: \\ Totem-Monument to the Political Prisoner, 1970}

Meireles planned Tiradentes around the inauguration of a new art space in Belo Horizonte in April 1970. The piece consisted of an eight-foot-tall wooden stake set into the ground with a clinical thermometer fixed to its top and a white cloth laid at its base. Ten hens were tied to the post, doused with petrol and burned alive (Figs. 8. 9). The title pays homage to the eighteenth-century Brazilian freedom fighter Joaquim José de Silva Xavier (1748-92). Known as Tiradentes, he organised the first uprising against Portuguese rule in 1789 and was subsequently hanged and quartered. In a jarring but intentional coincidence, the exhibition fell during the national, weeklong commemoration of the historical uprising; it was conceived as a part of a larger army initiative to appropriate the legend of Tiradentes as its own.

Fig. 8 and 9 Cildo Meireles (1970). Tiradentes: totem-monumento ao preso politico (Tiradentes: Totem-Monument to the Political Prisoner) [Courtesy: Atelier Cildo Meireles; photo: Luiz Alphonsus]
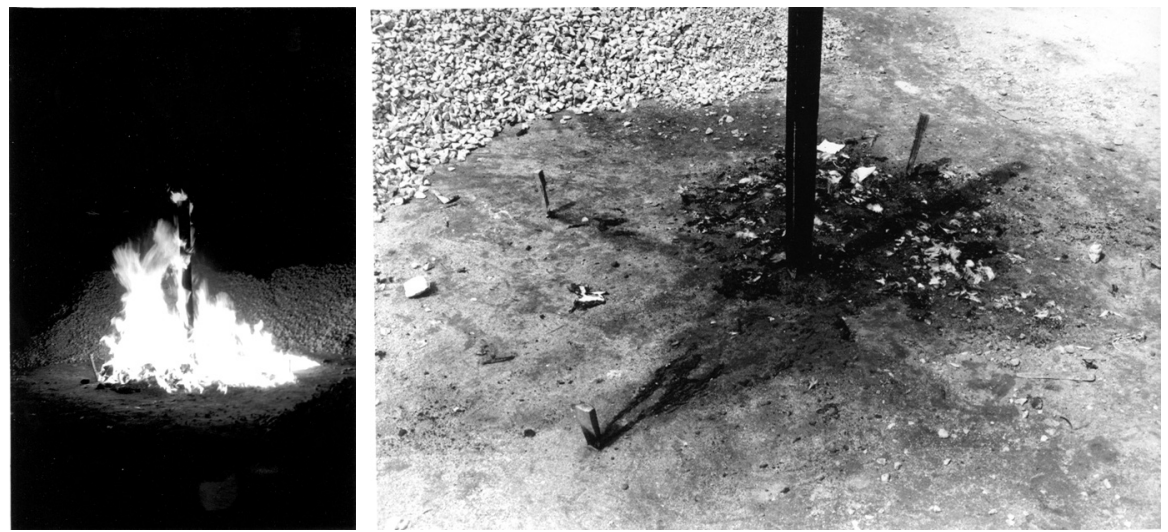

The piece was unquestionably meant as an indictment of the military regime, but Meireles intended it as well as an examination of material and sculptural space: "It's a work that could only exist in that format, with those materials, having a patent and profoundly painful relationship with the theme," he later explained, taking care to emphasise the work's material and ontological significance (Morais 2005: 61).

It expressed my beliefs and also responded to the demands of the artwork I was trying to produce. There were formal and conceptual aspects which were closely linked to the issue of the art object, and which had nothing to do with political discourse.

I was interested in metaphor and in the dislocation of the theme. I wanted to use the subject, life and death, as the raw material of the work. This dislocation is what matters in the history of the art object. (Mosquera 1999: 15)

Meireles has stressed the materiality of Tiradentes not to deny its violence but rather to point up the work's critical role within his constellation of ideological circuits and their mediations of power. The combustion of its materials literally exploded the sculptural field, introducing contingencies of life and death into the real space and time of the museum's opening. Tiradentes represented an extreme form of attack against ideology, and the visual spectacle of its trauma shifted the discourse more fully from concept to praxis. A rejoinder to the at times dryly-cerebral modes of conceptualism, Tiradentes drew purposefully on the visual drama and material transformations of sacrificial fire, which here hypostatised the threshold between art and life.

An incursion of greater magnitude than the Insertions into orbits of power, Tiradentes embodied contingency and its utopian corollary through the merging of 
pathos and pathology. The recourse to violence as a one-off condemnation of the human lives and freedoms lost reflected the exigency of contemporary political circumstances and, in the ideological terms of Meireles' practice, an entropic impulse spiralling toward dystopia. Meireles was at his most nihilistic here, and the futile immolation of the hens betrayed the cruel pathology at the farthest limits of utopian projection and the ultimate dematerialisation of sculptural form. The conceptual transfiguration of living beings into a "totem-monument" represented a scathing and improbable implosion of social and material space. As a performative mediation into what Meireles earlier called virtual spaces and ideological circuits, Tiradentes made real the contingencies of the world and of the non-object, here pushed toward a deeply existential end. The abjection of Tiradentes effectively denied utopia's escapist pull, and the formlessness of his totem-monument registered a morbid and harrowing critique of the regime in power.

Meireles left Brazil for New York in 1971, removing himself for a couple of years from the increasingly repressive measures of the military government, to participate in the international rise of conceptualism from a more central place. He adapted the Insertions for a North American audience and continued to probe the epistemic values of the art object, deployed through different and novel conceptual channels. Yet the material evolution of his practice between 1968 and 1970 was foundational both for his later work and for ontologies of the Brazilian non-object, whose discursive space he broke open and suggestively redeployed. From the visual parallax of Virtual Spaces: Corners to the autopoietic Insertions into Ideological Circuits and the incendiary Totem-Monument, Meireles posited the plasticity of increasingly and radically dematerialised forms. In this way re-characterising and expanding the sculptural field, he showed how the non-object could attain new functionality, making visible the vexed, pathological circuits of power and utopia. This tension between the ideological and ontological authority of an artwork crystallised in his practice by 1970 , and these paradigmatic early works suggest the changing conceptual horizons of sculpture and its capacity to condition our sense of the real. Meireles has continued to explore the landscape of sculpture in more recent work, notably in the form of installations that have probed the experience of sound (Babel, 2001), colour (Red Shift, 1967-84) and measurement (Fontes, 1992) - different systems that shape dematerialisation, as it were, in critical ways. Now celebrated as one of conceptualism's most significant and earliest interlocutors, Meireles has persisted in his commitment to the material expressiveness of art, even as his works engage different media.

The latent materiality of Meireles' earliest conceptual turn is often overlooked, but the reality check provided by his various and sundry material referents - architecture, consumer goods, living organisms - critically underlay his utopian conceits. Instrumentalised by invisible, ideological circuits, these quotidian objects pressured the boundary between material fact and immaterial mediation. They posited an interactivity that was both physical (as in the movement of bodies through space and objects through transactional hands) and conceptual (the negotiation of public and private spaces, the totemic monumentality of transubstantiated matter). The contingency and mutability of these materials were necessary conditions for Meireles' utopianism; indeed, the obduracy of their presence, even in autopoietic networks and incinerated remains, made specific and painfully real the ideological critique that girded his practice. Insinuated around the axis of medium and mediation, these material resonances ultimately reified - by virtue of their reality and their historicity - Meireles' many virtual spaces, locating his non-objects unmistakably in the real world. 


\section{References}

Celant, G. (1995). Claes Oldenburg: An anthology. New York, NY: Guggenheim.

Farmer, J. A. (2000). Through the labyrinth: An interview with Cildo Meireles. Art Journa/ 59(3), 34-43.

Fried, M. (1967). Art and objecthood. Artforum 5(10), 12-23.

Gullar, F. (1959, Sunday 20 December). Teoria da não-objeto. Jornal do Brasil.

McDevitt, J. (1965). Interviews with the new object makers, Richard Artschwager and Claes Oldenburg, on craftsmanship, art, and function. Craft Horizons XXV(5), 28-32, 54.

Meireles, C. (1999a). Insertions into ideological circuits. In P. Herkenhoff, G. Mosquera \& D.

Cameron (Eds.), Cildo Meireles (pp. 110-16). London, England: Phaidon.

Meireles, C. (1999b). Places for digressions: Interview with Nuria Enguita (extract) 1994. In P. Herkenhoff, G. Mosquera \& D. Cameron (Eds.), Cildo Meireles (pp. 136-40).

London, England: Phaidon.

Morais, F. (2005). Cildo Meireles: Drawings (1963-2005). In Cildo Meireles: algum desemho (19632005) (pp. 18-54). Rio de Janeiro, Brazil: Centro Cultural Banco do Brasil.

Mosquera, G. (1999). Gerardo Mosquera in conversation with Cildo Meireles. In P. Herkenhoff, G. Mosquera \& D. Cameron (Eds.), Cildo Meireles (pp. 6-35). London, England: Phaidon.

Ricoeur, P. (1987). Lectures on ideology and utopia. G. H. Taylor (Ed.). New York, NY: Columbia University Press. 